\title{
Fracture process of rubberized concrete by fictitious crack model and AE monitoring
}

\author{
Chao Wang ${ }^{1,2}$, Yamei Zhang*2 and Zhe Zhao ${ }^{2}$ \\ ${ }^{1}$ School of mechanics and materials, Hohai University, Nanjing, China, 210098 \\ 2 Jiangsu Key Laboratory of Construction Materials, Southeast University, Nanjing, China, 211189
}

(Received August 4, 2010, Revised January 24, 2011, Accepted March 23, 2011)

\begin{abstract}
According to the results of three-point bending tests of rubberized concrete and plain concrete, the parameters such as total fracture energy $\left(G_{F}\right)$, initial fracture energy $\left(G_{f}\right)$, and tensile strength $\left(f_{t}\right)$ are obtained for concrete material. Using ABAQUS software and a bilinear softening fictitious crack model, the crack propagation process was simulated and compared to the experimental results. It is found that the increase of $\mathrm{AE}$ hit count has a similar trend with the increase of energy dissipation in FEM simulation. For two types of concretes, both experimental results and numerical simulation indicate that the rubberized concrete has a better fracture resistance.
\end{abstract}

Keywords: concrete; fracture; acoustic emission; fictitious model.

\section{Introduction}

Classical fracture mechanics, which has been developed for over eighty years, is used to study strain field and stress field near crack tip. In 1961, fracture mechanics was applied to concrete area by Kaplan (1961) for the first time. But Kesler (1972) then found the theory was not able to illustrate the damage process in concrete precisely. Because concrete is a kind of quasi brittle material, applications of fracture mechanics in concrete is not the same as that used in metal. Therefore, in order to calculate crack propagation accurately, nonlinear models of fracture damage have to be used. Rashid (1968) developed a smeared crack model which revised the elastic matrix in the direction vertical to the cracks after damage. Hillerborg et al. (1976) proposed the fictitious crack model (FCM). FCM model has been widely used in the numerical simulation of concrete fracture. Baztant $(1982,1983,1984)$ proposed a crack band model (CBM) which is similar to FCM but including a crack width parameter. Recently some new methodology also has been used to simulate the concrete fracture, such as extended finite element method (XFEM) (Jog et al. 2007) and discrete element method (DEM) (Azevedo et al. 2006).

Acoustic emission (AE) as a nondestructive testing technology is widely applied in concrete damage research. Frequency components, rise time, and amplitude of AE signals have been used to distinguish different sources at different stress levels. The source location of an AE event can be determined based on the time differences among the recorded signals by an array of transducers, which has been used to monitor the microcrack localization in concrete and fiber reinforced concrete under uniaxial tension by Li and Shah (1994), and the fracture process zone in concrete under uniaxial

* Corresponding author, Professor, E-mail: ymzhang@seu.edu.cn 
tension by Maji and Shah(1988). Ohtsu et al. (1998) used moment tensor to analyze the concrete cracking process and found that, in the beginning of loading tensile cracks were primary and then the shear cracks became dominant. Chen et al. (2004) investigated the AE characteristics of threepoint bending concrete beams during the entire loading period. It was found that the relative notch depth significantly influenced the AE characteristics. Zhang et al. (2010) used the AE technology to study the fracture process of the rubberized concrete.

It has been widely accepted that rubber particles can improve the concrete fracture property. Reda Taha et al. (2008) studied the rubberized concrete with different rubber particle dosages. They found that the fracture energy had a peak value at rubber replacement ratio of $25 \%$. Considering the combined effect of tire rubber particles on both the compressive strength and fracture toughness, it seems that a replacement level around $25 \%$ of fine aggregate by chipped tire rubber particles might be an optimal replacement level producing enhanced fracture toughness without reducing much from the compressive strength.

In this article, a bilinear softening fictitious crack model, proposed by Hillerborg, was used to simulate the crack propagation process of both ordinary cement concrete and rubberized concrete. Besides, Acoustic Emission (AE) investigation was employed to monitor the bending process of concrete as well. The fracture process simulated by the fictitious crack model and that monitored by AE are compared.

\section{Specimen preparation}

In this research, Portland cement, river sand of 2.6 fineness modulus, 5-20 mm continuous grading limestone and 8-12 mesh rubber particles were used to prepare concrete. To study the improvement of fracture property, rubberized concrete is compared with three different strength plain concretes.

Table 1 Mix proportion of different types of concretes $\left(\mathrm{kg} / \mathrm{m}^{3}\right)$

\begin{tabular}{ccccccc}
\hline & W/C & C & W & S & G & R \\
\hline KB C50 & 0.53 & 377 & 200 & 729 & 1094 & - \\
RC C50 & 0.34 & 470 & 160 & 452 & 1168 & 63 \\
KB C60 & 0.40 & 425 & 170 & 614 & 1191 & - \\
KB C70 & 0.31 & 484 & 150 & 706 & 1060 & - \\
\hline
\end{tabular}

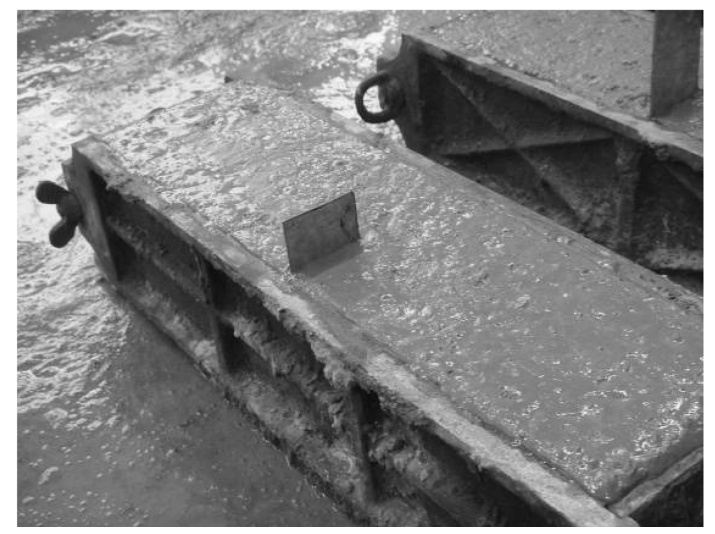

Fig. 1 Fresh concrete in the mold $(100 \mathrm{~mm} \times 100 \mathrm{~mm} \times 400 \mathrm{~mm})$ 
The mix proportion is shown in Table 1. All the specimens were cast into $100 \mathrm{~mm} \times 100$ $\mathrm{mm} \times 400 \mathrm{~mm}$ steel molds, and demolded after $24 \pm 2 \mathrm{~h}$. Then they were kept in a room for $28 \mathrm{~d}$ where the temperature was $20 \pm 3^{\circ} \mathrm{C}$ and the relative humidity was $90 \% \pm 2 \%$. A 2 mm thick metal sheet was used to make a $60 \mathrm{~mm}$ depth notch while concrete was still in its plastic state (Fig. 1).

\section{Three-point bending test}

The test instruments and system setup are shown in Fig. 2. The three point bending test was carried out with the MTS810 system. The span of the beam was $300 \mathrm{~mm}$ and the loading rate was controlled at $0.02 \mathrm{~mm} / \mathrm{min}$. In the testing process, load $(\mathrm{P})$, the crack mouth opening displacement (CMOD) and the acoustic signals were recorded by the MTS810 system and PCI-2 AE System (Fig. 3), separately.

R6 sensors (the resonance frequency is $60 \mathrm{kHz}$ ) were adhered on the surface of the specimen by Vaseline for AE signal collection (Fig. 3(b)). The threshold of AE signals is $40 \mathrm{~dB}$ and the preamplifier gain is $40 \mathrm{~dB}$. The location of AE sensors is shown in Fig. 3.

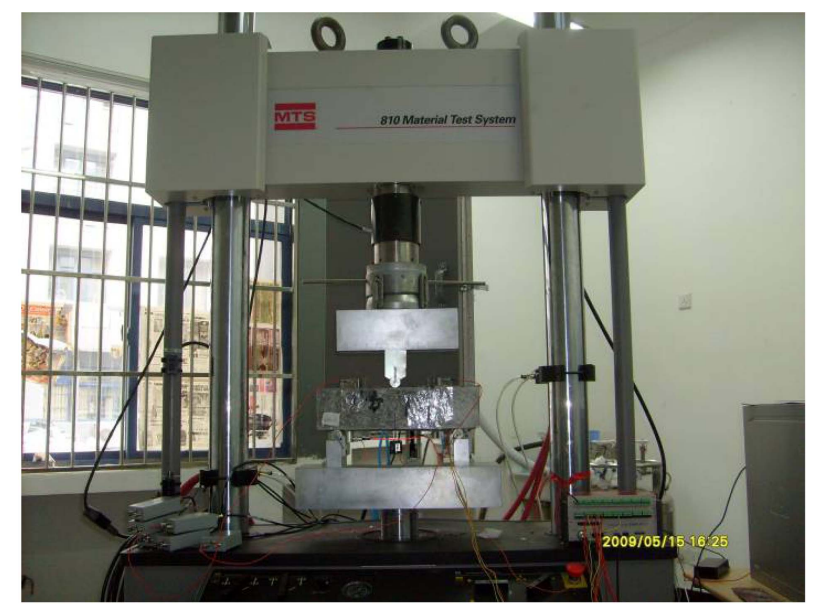

Fig. 2 Setup of MTS 810

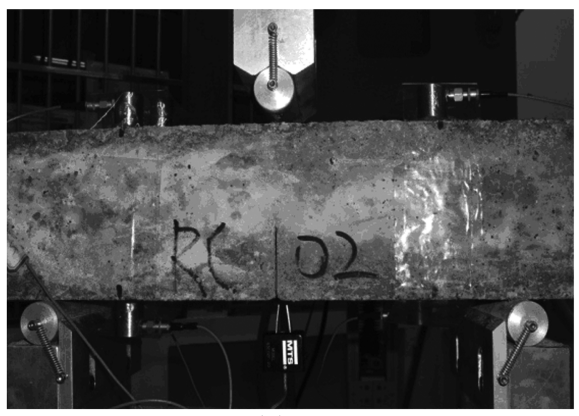

(a)

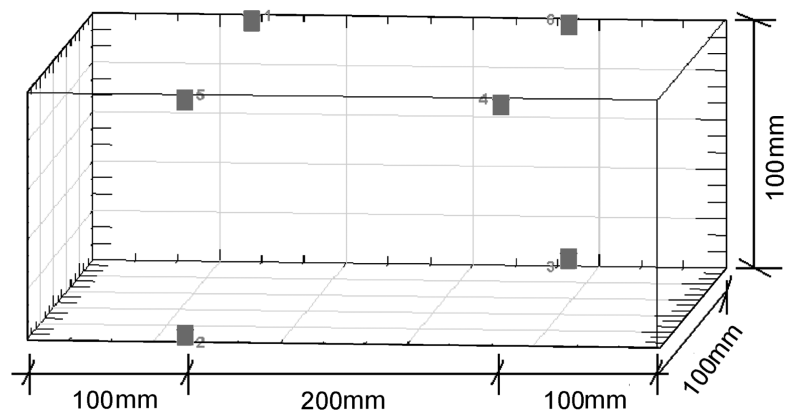

(b)

Fig. 3 Fracture test setup with COD gauge and AE sensors 


\section{Fracture test results and FEM simulation}

\subsection{Experimental results}

The three point bending test results are shown in Table 2 and Fig. 4. For the plain concretes, peak load is high, but CMOD is smaller at the peak load; the slope of the rising stage is higher and the curve near the peak becomes sharper. This indicates that, with the strength increasing, the concrete becomes more brittle.

Compared with plain concrete, the rubberized concrete has both higher peak load and larger fracture energy. It indicates the rubberized concrete has a good fracture resistance. It is because rubber particles have good deformability and good energy absorption, the stress concentration is alleviated when the microcracks extend to the surface of rubber particles.

Table 2 Results of the fracture test and other mechanical properties

\begin{tabular}{cccccc}
\hline & $\begin{array}{c}\text { Peak load/ } \\
\mathrm{kN}\end{array}$ & $\begin{array}{c}\text { Fracture energy/ } \\
\mathrm{N} \cdot \mathrm{m}^{-1}\end{array}$ & $\begin{array}{c}\text { Compressive } \\
\text { strength/MPa }\end{array}$ & $\begin{array}{c}\text { Bending strength } \\
/ \mathrm{MPa}\end{array}$ & $\mathrm{E} / \mathrm{GPa}$ \\
\hline KB C50 & 3.42 & 132 & 50.5 & 3.5 & 30.7 \\
RC C50 & 3.95 & 180 & 50.6 & 4.3 & 29.1 \\
KB C60 & 3.70 & 156 & 64.3 & 4.0 & 35.1 \\
KB C70 & 4.94 & 195 & 71.0 & 5.4 & 39.7 \\
\hline
\end{tabular}

$\mathrm{KB}$ : plain concrete; RC: rubberized concrete

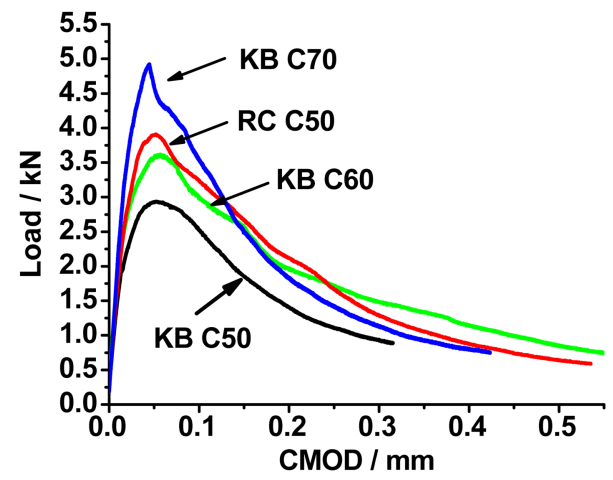

Fig. 4 The load versus CMOD curve

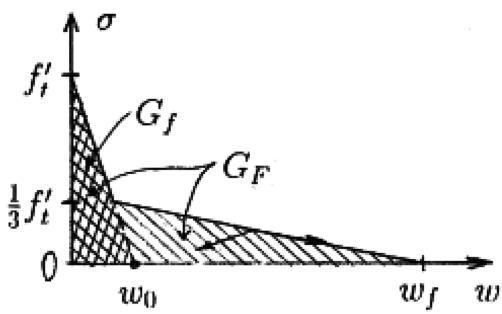

(a)

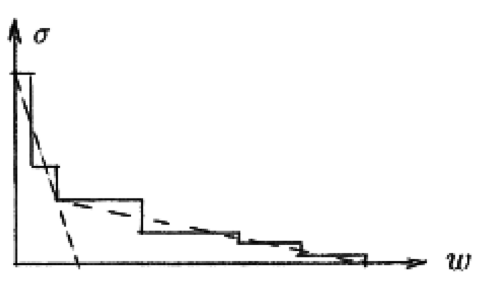

(b)

Fig. 5 (a) The bilinear softening displacement and (b) the practical relationship (Bazant 2002) 


\subsection{Finite element simulation}

\subsubsection{Fictitious crack model}

In this research, the FCM model, proposed by Hillerborg et al. (1976), was applied to simulate the fracture test process according to the parameters provided in Table 2, and the load/energy dissipation-displacement curves are obtained. For an opening crack, FCM treats the FPZ (fracture process zone) as a fictitious crack, and the cohesive force along FPZ is assumed as a function of the crack opening displacement (Fig. 5)

$$
\sigma=f(w)
$$

where, $\sigma$ is the cohesive force and $w$ is the crack opening displacement, $f(0)=f_{t}^{\prime}=$ tensile strength. The end of softening curve $f(w)$ is defined as $w_{f}, f\left(w_{f}\right)=0$. In this model, aggregates or broken parts on the crack surface causes viscoelastic force which is significantly different from continuum mechanics, for cohesive cracks detach obviously at the moment.

As a widely accepted and simplified softening model, bilinear curve needs two kinds of characteristic fracture energy:

$G_{F}$ - total fracture energy, which is defined as the area beneath curve of $f(w)$;

$G_{f}$ - initial fracture energy, which is the area between the tangent of curve $f(w)$ at $w=0$ and the $w$ axis. $G_{f}$ has a significant influence on the peak load of structure and the size effect.

In Eq. (1), there is a kink point located between $0.15 f_{t}^{\prime}$ and $0.33 f_{t}^{\prime}$. Before it, the cohesive force decreaed quickly; after this point, the slope of the curve changes gently. Therefore, the value of fracture energy $G_{F}$ has a great influence on the shape of the $f(w)$ curve. The fracture energy $G_{F}$ which means the energy needed by complete separation of unit area is the area below the softening curve $f(w)$.

\subsubsection{Cohesive element in ABAQUS and parameter setting}

ABAQUS was applied to simulate the energy dissipation during the fracture process. The meshing of elements is shown in Fig. 6. There are two kinds of element in the meshing of the model, one is ordinary linear-elastic elements (the blank elements in Fig. 6) and the other one is cohesive elements (the element 1-2-3-4 in Fig. 6). In $x$ direction of the cohesive element $(1 \rightarrow 2)$, there is only shear stress and no normal stress; while in the $y$ direction $(1 \rightarrow 4)$, there is only normal stress. The thickness of the unit can be set to 0 , so the model can be considered as two elastic elements

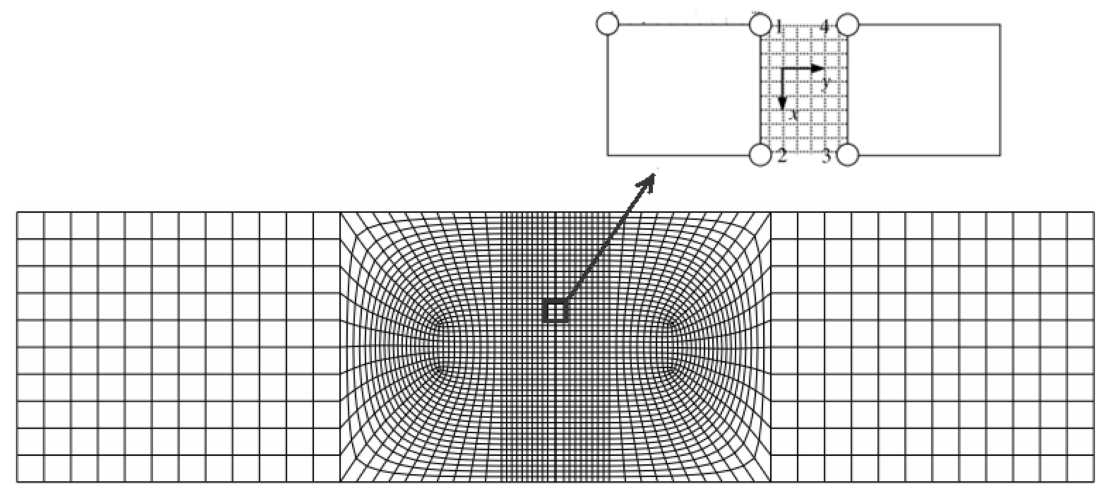

Fig. 6 Meshing and cohesive unit 


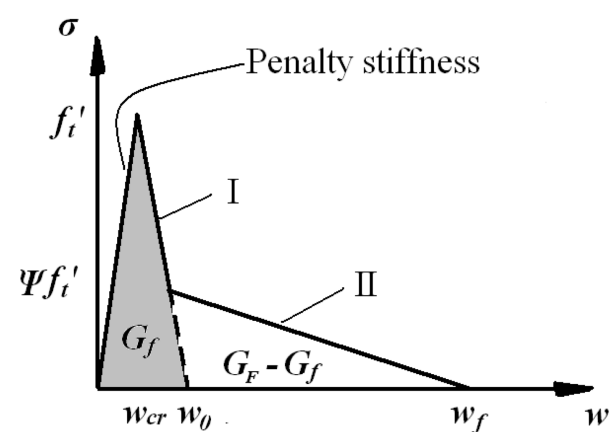

Fig. 7 The opening displacement of cohesive units under stress

adhered together by glue.

The model of cohesive element in ABAQUS is similar to Fig. 5(a), but there is a very steep ascent in the early stage, as shown in Fig. 7, because computers can not calculate a function which has an infinite slope. Therefore, the penalty stiffness (the ascending slope of the curve) should be set as big as possible if the calculation is stable.

Once the penalty stiffness is fixed (it is set as $1 \times 10^{13}$ after several tests), only five parameters need to be set: $G_{F}, E$ and $f_{t}^{\prime}$ are shown in Table 3; $G_{f}$ can be got by TPM (two-parameter fracture mode) (Shah et al. 1991) or size effect law (Bazant 1984). In this paper, $G_{f} \approx 0.4 G_{F}$; the kink point ratio $\Psi$ is generally between 0.15 and 0.33 (Bazant et al. 2002, Roesler 2007).
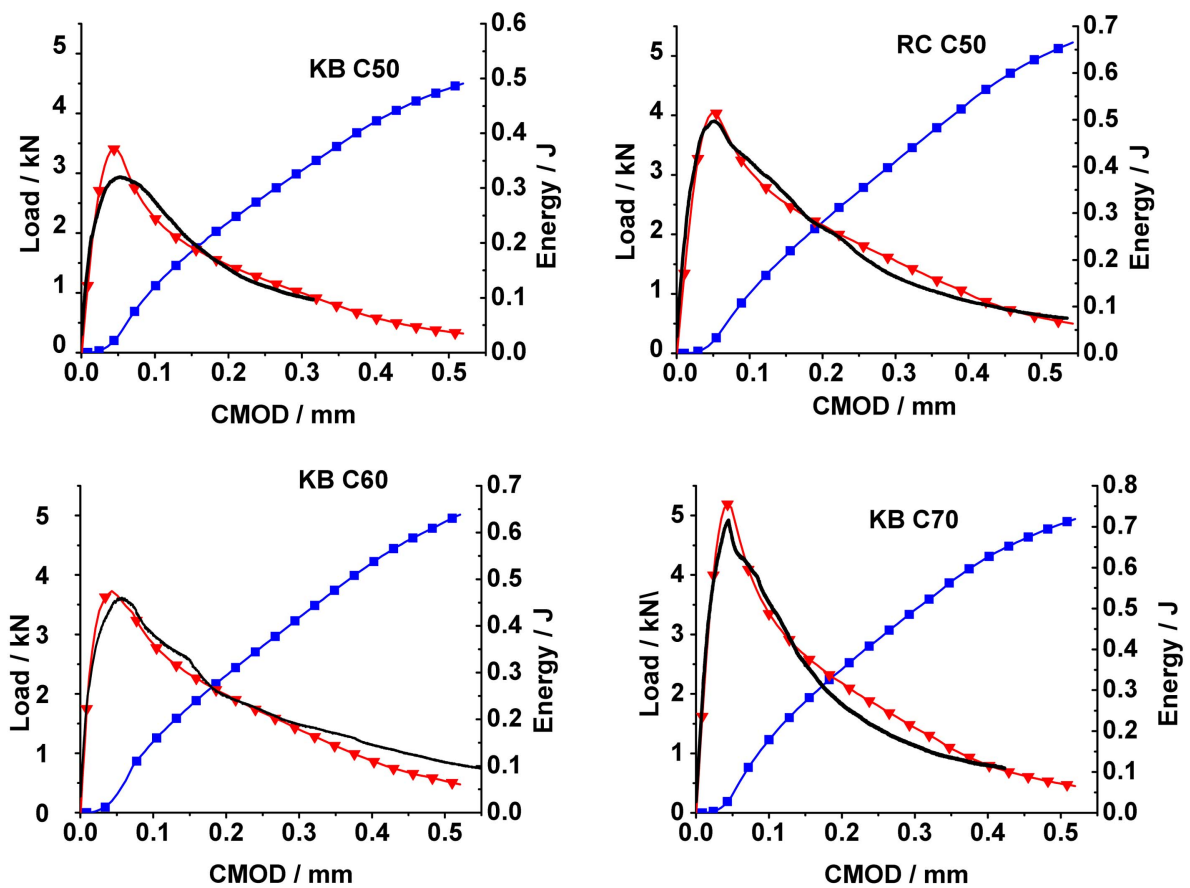

Fig. 8 FEM simulation and experimental results ( $\rightarrow-$ : Simulated dissipated energy, $\rightarrow-$ : Simulated load values, : measured load values) 


\subsubsection{Simulating results of concrete fracture}

Considering the discreteness of the experimental data, all the parameters are allowed to vary between $\pm 10 \%$ according to the test data. The simulating results are shown in Fig. 8 .

In Fig. 8, it can be seen that the fracture process simulated by FCM model is coincident with the practical experimental results. The simulated peak load increases with the strength, but the CMOD at peak load decreases. This indicates that the concrete becomes more brittle with strength growth. Before the peak load, the energy dissipation is small; after the peak load, it increases quickly; and with the declining curve becoming flater, the energy dissipation also slows down.

\section{Acoustic emission (AE) investigation}

\subsection{AE monitoring results}

Fig. 9 shows the development of the cumulative AE hit count with crack mouth opening. As shown in the figures, at the initial cracking phase, the hit count increases slowly; after the load rising close to the peak load, the hit rate starts increasing. While, before the peak load, the hit count is less than $10 \%$ of the total hit count in each specimen. This indicates that the initial crack has not propagated on a large scale. After the peak load, the load falls but the hit count still increases rapidly. It means that macro crack propagates quickly and a large FPZ is formed. Compared with Fig. 8, it can be found that the increase of the AE hit count has a similar trend to the energy dissipation, because the acoustic emission signals are produced from the releasing of the strain
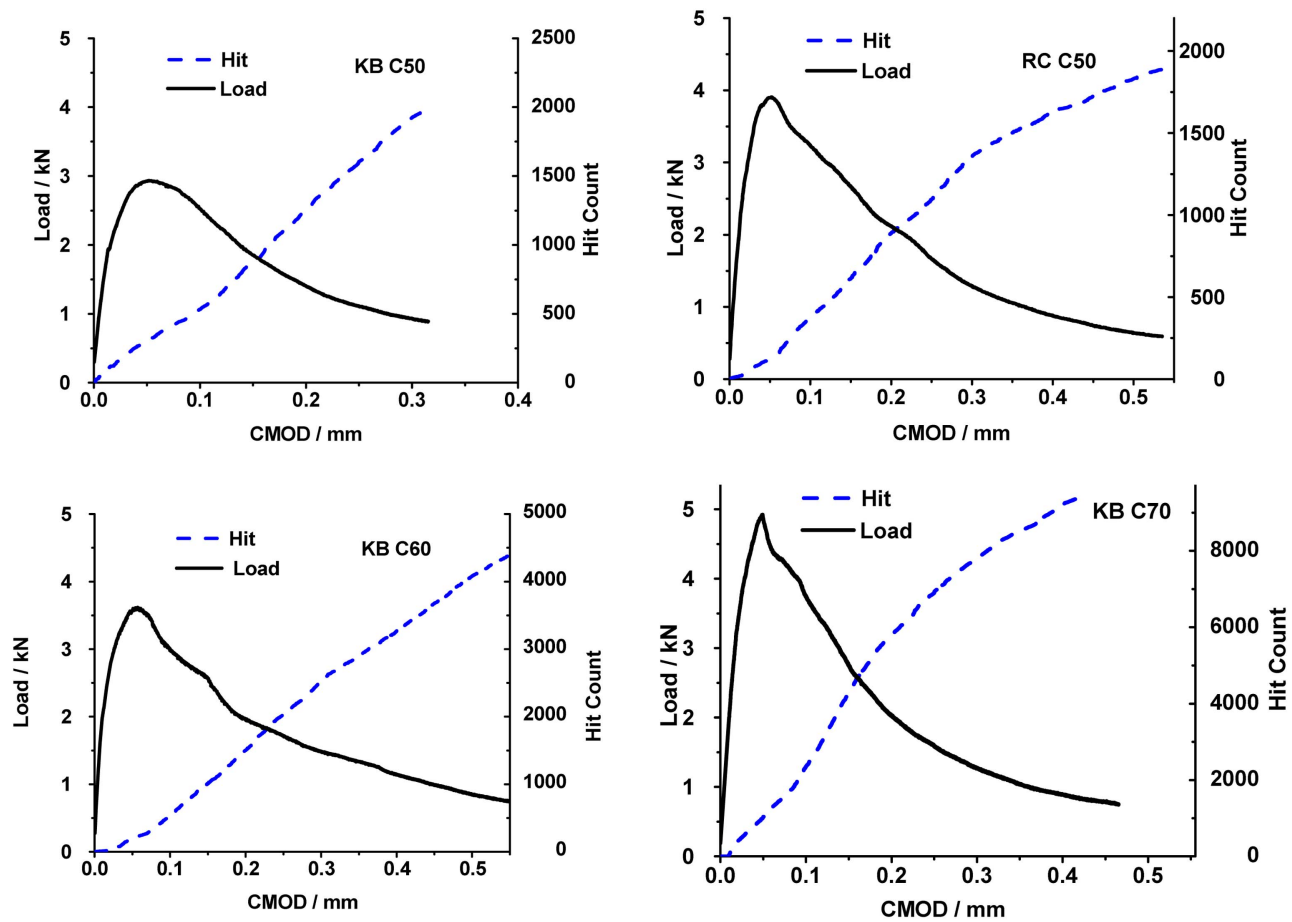

Fig. 9 Load and cumulative hit count versus crack opening displacement 


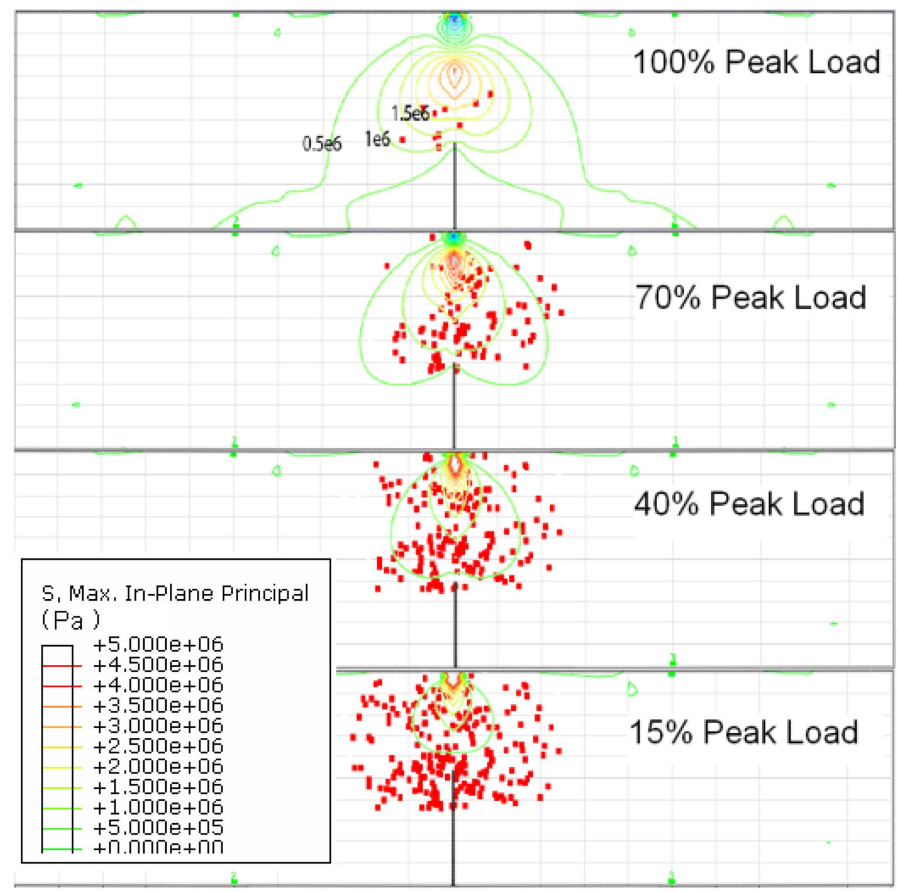

Fig. $10 \mathrm{AE}$ location and contour diagram of stress $\sigma_{1}$ after peak load of plain concrete

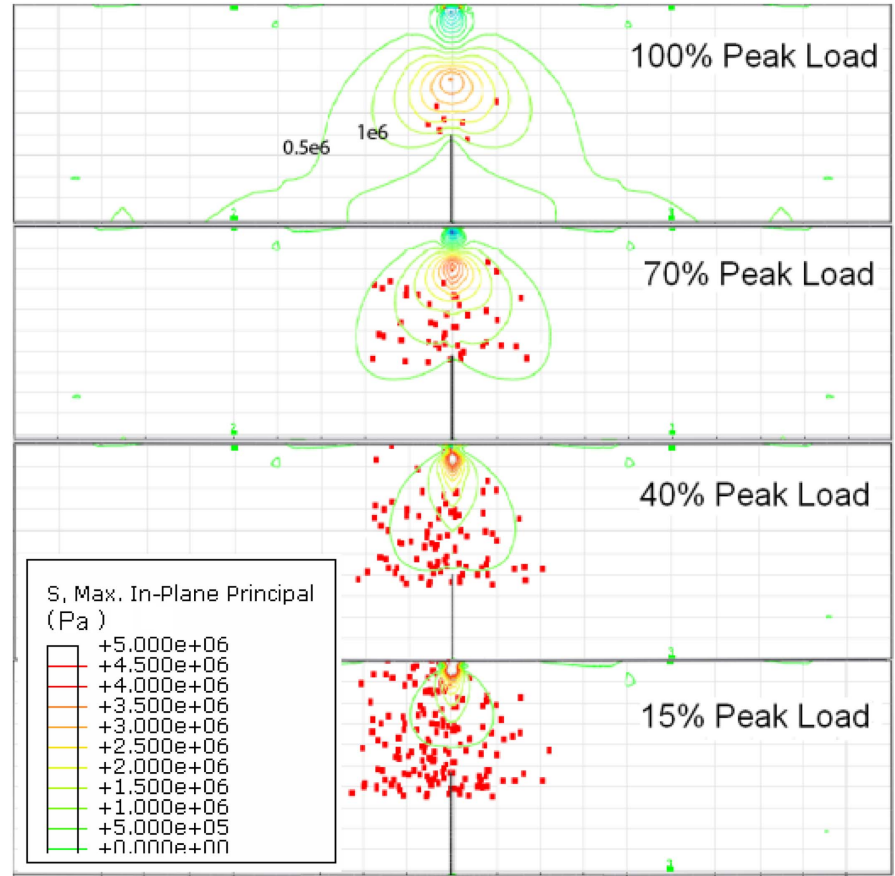

Fig. 11 AE location and contour diagram of stress $\sigma_{1}$ after peak load of rubberized concrete 
energy, and acoustic emission also is a form of the energy dissipation.

AE analysis software AEwin (produced by Physical Acoustic Corporation) was used to calculate the location of $\mathrm{AE}$ events. The $2 \mathrm{D} \mathrm{AE}$ locations which are projected to the plane vertical to the initial crack from 3D loaction and maximum normal stress contour diagram (generated by ABAQUS software) of KB C50 and RC C50 are shown in Figs. 10 and 11, respectively. It can be seen that most of the AE events happen in front area of the notch tip, which means most AE signals are along the FPZ. With the propagation of the FPZ, the AE events stretch to the top of the specimen, and the maximum stress moves towards the top of the specimen as well.

The calculated energy dissipation density by FCM model and statistical AE event count in every 2 $\mathrm{mm}$ along the cracking path are shown in Figs. 12 and 13. At the peak load, the dissipated energy density and AE event count are both low, and the FPZ is small; with the propagation of cracks, the dissipated energy density and event count both increase quickly; after about $70 \%$ post peak load, the

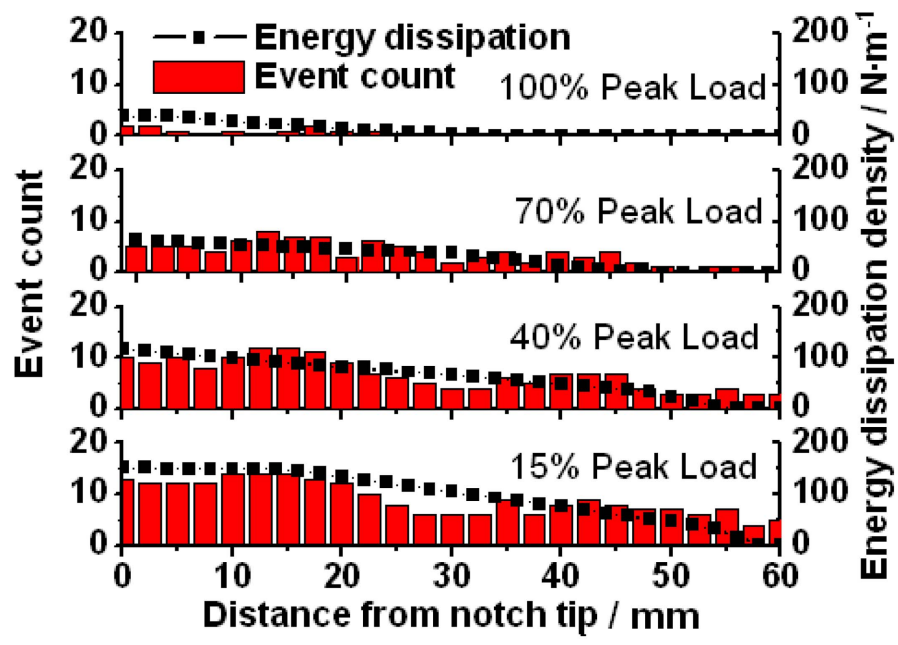

Fig. $12 \mathrm{AE}$ events count in fracture path of plain concrete

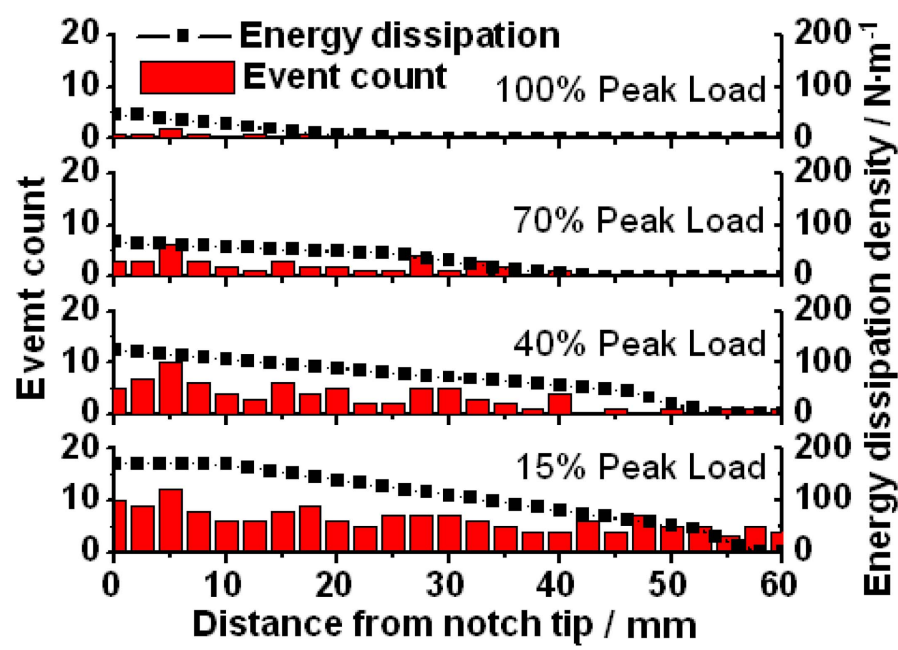

Fig. $13 \mathrm{AE}$ events count in fracture path of rubberized concrete 
FPZ expands to the top of the specimen. Comparing both concretes, the FPZ of the rubberized concrete increases more slowly than ordinary concrete, although both have a close bending strength and peak load.

\subsection{Discussion}

As Figs. 10 to 13 show, before peak load, the fictitious crack (the elements between the notch tip and maximum stress which can be considered at the center of the maximum stress contour) is small and most part in the fracture path is still in the elastic phase. The stress contour figures also show that stress in most part of the fictitious crack is larger than $\Psi f_{t}^{\prime}$ which indicates that elements are in the first cracking phase (see Fig. 7). According to the bilinear model, the energy dissipation in the first phase $\left(G_{f}\right)$ only takes a small part of total fracture energy $\left(G_{F}\right)$. These explain the reason why both $\mathrm{AE}$ hit count and events are low at the peak load. With the crack propagation, the fictitious crack extends to top of the specimen and most elements are in the second cracking phase. The large energy dissipation causes the detected AE signals to increase quickly. After the opening displacement of fictitious crack gets larger than $w_{f}$, the cohesive elements fail and the real crack is formed. As a result, the speed of energy dissipation and the new AE signals decreases.

\section{Conclusions}

This study has investigated the fracture process of plain concrete and rubberized concrete with AE technique and FEM simulation method. The following conclusions can be drawn:

1. The fracture energy increases with the strength growth of concrete and the incorporation of the rubber particle in concrete can result in a better ductility and higher fracture energy due to the good deformability of rubber particles which may release the local stress concentration when micro cracks extend to the surface of rubber particles.

2. According to the bilinear softening fictitious cracking model, the fracture process is simulated by ABAQUS software. Compared with the load-CMOD curve, the simulated results agreed with the real test.

3. AE hit count growth during the fracture process has a similar trend to that of energy dissipation. Although rubberized concrete shows higher fracture energy than plain concrete, the AE signals detected is not higher due to the sound adsorption effect of rubber particles.

4. The AE location indicates that the AE signals are generated along the simulated fictitious crack. So the energy dissipation during the fracture process of concrete can be characterized by $\mathrm{AE}$ hit/event count.

\section{Acknowledgements}

The study of this paper is financially supported by National Natural Science Foundation of China (Grant No. 50778039) and National Basic Research Program of China (973 Program) (Grant No. 2009CB623200). 


\section{References}

Azevedo, M.N. and Lemos, J.V. (2006), "Hybrid discrete element/finite element method for fracture analysis", Comput. Method. Appl. M., 195, 4579-4593.

Bazant, Z.P. (1982), "Crack band model for fracture of geomaterials", Eisentein Z, editor, Proceedings of the 4th International Conference on Numerical Methods in Geomechanics, Vol. 3, Edmonton, Alberta, 1137-1152.

Bazant, Z.P. (1983), "Fracture in concrete and freinforced concrete", Bazant ZP, editor, Preprints, IUTAM prager Symposium on Mechanics of Geomaterials: Rocks, Concretes, Sorls, Northwestern University, Evanston, 281-316.

Bazant, Z.P. (1984), "Size effect in blunt fracture: concrete, rock, metal", J. Eng. Mech. - ASCE, 110, 518-535.

Bazant, Z.P. (2002), "Concrete fracture models: testing and practice", Eng. Fract. Mech., 69(2), 165-205.

Bazant, Z.P. and Oh, B.H. (1983), "Crack band theory for fracture of concrete", Mater. Struct., 93, 155-166.

Bazant, Z.P., Yu, Q. and ZI, G. (2002), "Choice of standard fracture test for concrete and its statistical evaluation", Int. J. Fracture, 118, 303-337.

Chen, B. and Liu, J. (2004), "Experimental study on AE characteristics of three-point-bending concrete beams", Cement Concrete Res, 34, 391-397.

Hillerborg, A., Modeer, M. and Petersson, P.E. (1976), "Analysis of crack formation and crack growth in concrete by means of fracture mechanics and finite elements", Cement Concrete Res., 6, 773-782.

Jog, F.U., Stefan, E. and Carsten, K. (2007), "Modelling of cohesive crack growth in concrete structures with the extended finite element method", Comput. Method. Appl. M., 196, 4087-4100.

Kaplan, M.F. (1961), "Crack propagation and the fracture concrete", ACI J., 58(11), 591-610.

Kesler, C.E., Naus, D.J. and Lott, J.L. (1972), "Fracture mechanics - its applicability to concrete", Proceedings of the International Conference on the Mechanical Behavior of Materials, Vol. IV, Kyoto, 1971, The Society of Materials Science, 114-124.

Li, Z. and Shah, S.P. (1994), "Localization of microcracking in concrete under uniaxial tension", ACI Mater. J., 91(4), 372-381.

Maji, A. and Shah, S.P. (1998), "Process zone and acoustic emission measurement in concrete", Exper. Mech., 28(1), 27-33.

Ohtsu, M., Okamoto, T. and Yuyama, S. (1998), "Moment tensor analysis of acoustic emission for cracking mechanisms in concrete", ACI Struct. J., 95, 87-95.

Rashid, Y.R. (1968), “Analysis of prestressed concrete pressure vessels”, Nucl. Eng. Des., 7, 334-344.

Reda, T.M., El-Dieb, A.S. and Abd El-Wahab, M.A. (2008), "Mechanical, fracture, and micro-structural investigations of rubber concrete", J. Mater. Civil Eng., 20, 640-649.

Roesler, J., Paulino, G.H., Park, K. and Gaedicke, C. (2007), "Concrete fracture prediction usiong bilinear softening", Cement Concrete Compos., 29, 300-331.

Shah, S. and Carpinteri, A. (1991), Fracture mechanics test methods for concrete, RILEM, Chapman and Hall, London.

Zhang, Y., Wang, C., Lu, Y. and Ma, A. (2010), "Comparison of the fracture process of rubberized concrete and plain concrete under bending load", Sci. China: Tech. Sci., 53(1), 1-8.

$C C$ 